\title{
Influence of acute coronary syndromes in clinical outcome of patients with acute heart failure
}

\begin{abstract}
Background: A substantial proportion of hospitalized patients with coronary heart disease develop acute heart failure (HF) during the hospital stay, and have a worse prognosis in those patients who develop acute HF at the initial presentation.

Methods: In a retrospective cohort study, we stratified the enrolled acute HF patient population into two groups: Group I: adult patients admitted with a diagnosis of acute HF secondary to acute coronary syndrome (ACS). Group II: adult patients admitted with a diagnosis of acute HF secondary to other causes not related to ACS, during January 2015 to December 2016. We aimed to determine the frequency of cardiovascular complications, triggering causes, clinical profile and cardiovascular risk factors in patients with acute HF secondary to ACS in comparison to those patients without ACS
\end{abstract}

Results: We found significant differences in the forms of presentation of acute HF. In the acute HF with ACS cohort the de novo HF was more frequent (19\%), while the acute on chronic HF was more frequent in the acute HF without ACS cohort $(94 \%)(\mathrm{p}=0.001) .90 \%$ of patients with ACS and $99 \%$ of patients without ACS were in hospital admission in NYHA functional class III-IV $(\mathrm{p}=0.001)$. Patients with ACS were more susceptible to develop shock during hospitalization (cardiogenic, noncardiogenic and mixed), with a RR of $1.2(0.7-2.1)$ for the overall shock $(\mathrm{p} .=0.4)$. Complications such as acute pulmonary edema, malignant ventricular arrhythmias, stroke, and cardio-renal syndrome were more frequent in patients with acute HF with ACS. Cardiovascular death, multifactorial death, and sudden death were more frequent in patients in the acute HF with ACS group. Septic deaths were more frequent in HF patients without ACS.

Conclusion: ACS as a precipitating factor of HF is a distinct clinical entity, with a particular Pathophysiology and a different clinical outcome compared with other causes of heart failure. In addition, it is associated with more adverse cardiovascular events in the evolution, therefore, it should be considered for the early initiation of therapeutic strategies in order to improve the prognosis of this group of patients.

Keywords: acute heart failure, acute coronary syndrome, clinical outcome, cardiovascular death
Volume II Issue 5 - 2018

\author{
Christian Osmar Chávez-Alfonso,' Osmar \\ Antonio Centurión ${ }^{1,2}$ \\ 'Division of Cardiovascular Medicine, Clinic Hospital,Asuncion \\ National University (UNA), San Lorenzo, Paraguay \\ ${ }^{2}$ Department of Health Sciences Investigation, Sanatorio \\ Metropolitano, Fernando de la Mora, Paraguay
} Correspondence: Osmar Antonio Centurión, Professor
of Medicine. Asunción National University-UNA, Division of
Cardiovascular Medicine, Clinic Hospital, Paraguay, Tel +(595) 971 354444,Email osmarcinturion@hotmail.com

Received:September 17, 2018 | Published: October 24, 2018
Abbreviations: ACS, acute coronary syndrome; DM, Diabetes mellitus; TIA, transient ischemic attack.

\section{Introduction}

Heart failure (HF) is a clinical syndrome characterized by typical symptoms such as dyspnea, edema and fatigue, which may be accompanied by signs such as elevated jugular venous pressure, pulmonary crackles and peripheral edema. HF may be caused by a structural and/or functional cardiac abnormality, resulting in a reduced cardiac output and/or elevated intracardiac pressures at rest or during stress. $^{1-5}$

Acute heart failure is defined as a rapid worsening of the signs and symptoms of HF and it needs urgent treatment. ${ }^{6-10}$ It is a clinical syndrome with a complex Pathophysiology which is not completely understood. Given the diversity of clinical presentations, several different physio-pathological mechanisms along with triggering factors of circulatory decomposition are involved. Events that precipitate acute decomposition mainly consist of ischemia, hypertension, arrhythmias, non-cardiac comorbidities, and administered drug agents. ${ }^{4}$
Up to $15-20 \%$ of patients admitted for acute coronary syndrome (ACS) have signs and symptoms of HF at presentation, and another $10 \%$ develop HF during the hospital stay. The incidence is even higher in studies that focus on patients diagnosed with acute HF, in these patients the triggering factor is an acute coronary syndrome in up to $40 \%$. It is interesting to note that currently ACS complicated by acute HF is often considered a distinct clinical entity, characterized by structural, hemodynamic and neurohormonal complex interactions, which require urgent coronary intervention. It is usually associated with poor outcome and worse prognosis compared with other patients with acute $\mathrm{HF}$ triggered by other causes. ${ }^{4}$

Heart failure continues to be a significant cause of morbidity and mortality worldwide, ${ }^{11-15}$ and over a half of patients with acute HF admitted to the hospital have a history of coronary heart disease. ${ }^{16-20}$ ACS complicated by acute HF leads to a several-fold increase in hospital mortality compared to those without acute HF. In addition, a substantial proportion of hospitalized patients with coronary heart disease develop acute HF during the hospital stay, and have a worse prognosis in those patients who develop acute HF at the initial presentation. ${ }^{12}$ 
Acute HF represents a syndrome that has a heterogeneous Pathophysiology with variable results. Therefore, it is interesting to compare a group with unique Pathophysiology and therapeutic objectives as represented by acute HF due to ACS, with those patients who present with acute HF without ACS. Consequently, the prevalence, clinical evolution and the therapies established will be determined. In addition, the incidence of cardiovascular complications and mortality will be determined by comparing both groups of patients with acute HF.

\section{Objectives}

\section{Primary}

To determine the frequency of cardiovascular complications in patients with acute HF secondary to ACS in comparison with those patients without ACS.

\section{Secondary}

i. To describe cardiovascular complications in patients with acute HF.

ii. To determine the frequency of patients admitted to the hospital with the diagnosis of acute HF with and without ACS.

iii. Describe the most frequent triggering causes of acute HF.

iv. Describe the demographic characteristics, clinical profile and cardiovascular risk factors, therapies and outcomes in patients presenting acute HF with and without ACS.

\section{Material and methods}

Design: A retrospective cohort study

Population: For this analysis, we stratified the enrolled acute HF patient population into two groups:

Cohort 1: adult patients admitted to the "Hospital de Clínicas" with a diagnosis of acute HF secondary to ACS, from January 2015 to December 2016.

Cohort 2: adult patients admitted to the "Hospital de Clínicas" with a diagnosis of acute HF secondary to other causes not related to ACS, from January 2015 and December 2016.

\section{Inclusion criteria}

i. Patients diagnosed with acute HF according to the Guidelines of the European Society of Cardiology and the American College of Cardiology for the diagnosis and management of acute HF.

ii. Patients diagnosed with ACS based on the symptoms and clinical context, on electrocardiography and the levels of cardiac biomarkers.

iii. The definitions for STEMI and NSTEMI were based on the European Society of Cardiology and the American College of Cardiology clinical data standards.

Exclusion criteria: Patients who do not meet the inclusion criteria.

Sample: Non-Probability Sampling. Consecutive sampling.

\section{Variables}

i. Independent variable: acute coronary syndrome (dichotomous) ii. Dependent: days of hospitalization, refractory or recurrent heart failure, acute pulmonary edema, cardiogenic or non-cardiogenic or mixed shock, stroke, sepsis, requirement of mechanical ventilation in the ICU, malignant arrhythmias (VT/VF), hospital death.

\section{Other variables}

a. Demographic: age, sex, origin.

b. Medical history: heart failure, ischemic heart disease, valvular heart disease, chronic atrial fibrillation, stroke/TIA, COPD, chronic kidney disease, chronic liver disease, thyroid disorders, rheumatologic disease, chronic anemia. Risk factors for atherosclerosis: diabetes mellitus, hypertension, smoking, dyslipidemia.

c. Triggering factors: acute coronary syndrome, arrhythmias, pulmonary embolism, anemia, drugs, non-adherence to medication, non-adherence to diet, abandonment of medication, infection, volume overload, valvular, pericardial, cardiomyopathy.

d. Clinical parameters on presentation: systolic blood pressure, diastolic blood pressure, heart rate, body mass index.

e. Acute Heart Failure type in presentation: Acute de novo and acute on chronic HF.

f. Functional Classification: NYHA class. Findings in Electrocardiography: Atrial fibrillation, atrial Flutter, Left Bundle Branch Block, prolonged QRS (>120 ms).

g. Biochemical parameters: plasma sodium, plasma potassium, urea, creatinine, estimated glomerular filtration rate, hemoglobin, glycemia, albumin, NT-PRO-BNP, positive troponins, echocardiography findings (Left ventricular ejection fraction), coronary angiography findings.

h. Treatments received in hospital: beta-blockers, ACEI, ARB II, aldosterone antagonist, loop diuretics, inotropic and vasopressors.

Sample size estimation: the sample size was estimated using EPI Info statistical software version 7.2.0.1 (EPI Info, Center for Disease Control). We estimated the strength of the associations of these groups using $95 \%$ confidence intervals, power of $80 \%$, Reason of $1: 1$. Mortality rate of $5 \%$ in cohort 1 , and $12 \%$ in cohort 2 . We calculated a minimum sample size (n) of 200 patients. ${ }^{13,14}$

Statistical analysis: The variables were recorded in the Excel 2007 spreadsheets. The analysis was performed using EPI Info statistical version 7.2.0.1 and Epidat 3.1 software's. The qualitative variables were expressed in frequencies and percentages, and the quantitative variables in means and standard deviations (SD); or as medians and interquartile ranges. The comparisons between the two cohorts were performed using the chi-square statistical test for the qualitative variables, expressed as Relative Risk. We estimated the strength of the associations of these groups using $95 \%$ confidence intervals and a p-value $<0.05$ was considered statistically significant. Comparisons of the quantitative variables between both cohorts were performed using the Bartlett's test to verify the homogeneity of variances. In the cases of variance homogeneity, statistical significance was determined with the ANOVA test. In cases without homogeneity of variances, statistical significance was determined using the nonparametric tests of Mann Whitney Wilcoxon and Kruskal Wallis. 


\section{Results}

We included 233 patients with acute HF in this study, of which 72 $(31 \%)$ were secondary to ACS and $161(69 \%)$ were triggered by other causes. The precipitating causes of acute HF are depicted in Table 1.

Of the cases diagnosed at admission with ACS $65 \%$ were NSTEMI, 19\% STEMI and 15\% Unstable Angina. Comparing both groups, cohort 1 (with ACS) had a mean age 2 years older $(66 \pm 12$, $\mathrm{p}=0.2)$. The female sex was higher in cohort $1(57 \%)$, while the male sex predominated in cohort 2 (without ACS) $(57 \%)(\mathrm{p}=0.04)$. The baseline characteristics can be seen in Table 2 .

Previous history of HF was significantly higher in the acute HF without ACS cohort $(p<0.001)$. Comorbidities such as anemia, rheumatological disease, atrial fibrillation, valvular heart disease, chronic lung disease, chronic kidney disease and liver disease were predominant in these patients without statistically significant difference, except for valvular disease $(\mathrm{p}=0.004)$.

We found significant differences in the forms of presentation of acute HF. In the acute HF with ACS cohort the de novo HF was more frequent $(19 \%)$, while the acute on chronic HF was more frequent in the acute HF without ACS cohort $(94 \%)(\mathrm{p}=0.001) .90 \%$ of patients with ACS and $99 \%$ of patients without ACS were in hospital admission in NYHA functional class III-IV $(\mathrm{p}=0.001)$. Patients without ACS tended to be more obese, median BMI of 31 (IQR 29-33) ( $p=0.6)$, had a higher heart rate (mean $91 \pm 20, \mathrm{p}=0.2$ ), and had a higher proportion of atrial fibrillation / flutter $(35 \%)(\mathrm{p}=0.2)$. In contrast, patients with ACS had higher blood pressure (mean SBP $135 \pm 22, \mathrm{p}=0.3$, mean DBP $80 \pm 15, \mathrm{p}=0.5$ ) and had a higher proportion of complete left bundle branch block $(15 \%)(\mathrm{p}=0.09)$ and a longer $\mathrm{QRS}$ interval $\geq 120 \mathrm{~ms}$ $(15 \%)(\mathrm{p}=0.007)$.

Table I Precipitating causes of acute heart failure

\begin{tabular}{|c|c|c|c|}
\hline Precipitating factors & $\%$ patients $(n=233)$ & $\begin{array}{l}\% \text { patients with } \\
\text { ACS }(n=72)\end{array}$ & $\begin{array}{l}\% \text { patients without } \\
\text { ACS }(n=161)\end{array}$ \\
\hline Non-adherence to medication & 52 & 35 & 60 \\
\hline Infection & 48 & 36 & 53 \\
\hline ACS & 31 & 100 & 0 \\
\hline Arrhythmia & 16 & 8 & 19 \\
\hline Valvular & 10 & 4 & 13 \\
\hline Non-adherence to diet & 8 & 0 & II \\
\hline Abandonment of treatment & 6 & I & 7 \\
\hline Uncontrolled hypertension & 5 & 4 & 5 \\
\hline No treatment & 4 & 3 & 4 \\
\hline Anemia & 3 & 1 & 4 \\
\hline Pericarditis/Pericardial effusion & 2 & 0 & 3 \\
\hline Stroke/TIA & 2 & 0 & 2 \\
\hline Decompensated DM & 2 & 1 & 2 \\
\hline Pulmonary hypertension & 2 & 0 & 2 \\
\hline
\end{tabular}

Regarding the biochemical parameters, we did not find statistically significant differences between both groups, except in the presence of positive troponin, which predominated in the acute HF with ACS cohort $(83 \%)(\mathrm{p}<0.001)$. Also, hyponatremia $(\mathrm{Na}<135)$ that predominated in the AHF without ACS cohort (39\%) ( $\mathrm{p}=0.03)$. Patients with ACS had a tendency to a higher glycemia with a mean of $142 \pm 72(\mathrm{p}=0.05)$ and to have a lower eGFR, mean of $58 \pm 34(\mathrm{p}=0.2)$. The mean of EF was lower in the patients with ACS (mean 48 \pm 14 , $\mathrm{p}=0.1)$. In addition, ventricular dysfunction $(\mathrm{FE}<50 \%$ ) was found more frequently in patients in this group $(54 \%, \mathrm{p}=0.2)$. There was no statistically significant difference between both groups regarding the treatment with ACEI, ARB and beta-blockers, as can be seen in Table 3.

Abbreviations: ACS, acute coronary syndrome; ACEI, angiotensin-converting enzyme inhibitor; AHF, acute heart failure; ARB, Angiotensin II receptor blockers; CAD, coronary artery disease; PCI, Percutaneous Coronary Intervention.

In contrast, patients without ACS used loop diuretics $(\mathrm{p}=0.005)$ and antialdosterone diuretics more frequently $(\mathrm{p}<0.001)$. Patients with ACS required more vasopressors $(14 \%$ vs. $10 \%, \mathrm{p}=0.3)$, and similar inotropic requirement with the other group $(12 \%)(\mathrm{p}=0.8)$.

Patients in the acute HF with ACS arm tended to present some type of significant coronary lesion, with the predominant finding being three-vessel CAD (35\%). Non-significant coronary stenosis was more frequent in the other arm acute HF without ACS (44\%).

No statistically significant differences were found when comparing both groups in terms of the complications presented during hospitalization, as can be seen in Table 4 . 
Table Continued..

\begin{tabular}{|c|c|c|c|}
\hline Precipitating factors & $\%$ patients $(n=233)$ & $\begin{array}{l}\% \text { patients with } \\
\text { ACS }(n=72)\end{array}$ & $\begin{array}{l}\% \text { patients without } \\
\text { ACS }(n=\mid 6 I)\end{array}$ \\
\hline Cocaine use & I & I & I \\
\hline Other drugs & I & 0 & I \\
\hline Pulmonary embolism & I & 0 & 2 \\
\hline Cardiac tamponade & I & I & I \\
\hline Volume overload & I & 0 & I \\
\hline Myocarditis/Myocardiopathy & I & 0 & 1 \\
\hline
\end{tabular}

Table 2 Demographic and clinical characteristics of patients with acute heart failure with and without acute coronary syndrome

\begin{tabular}{|c|c|c|c|c|}
\hline & Overall (n: 233) & $\begin{array}{l}\text { AHF with ACS n=72 } \\
(31 \%)\end{array}$ & $\begin{array}{l}\text { AHF without ACS } n=|6| \\
(69 \%)\end{array}$ & $P$ value \\
\hline \multicolumn{5}{|l|}{ Demographics } \\
\hline Age, years; mean \pm SD & $65 \pm 14$ & $66 \pm 12$ & $64 \pm 14$ & $0.2^{*}$ \\
\hline Male, n (\%) & $123(53)$ & $31(43)$ & $92(57)$ & 0.04 \\
\hline Female, n (\%) & I I0 (47) & $4 \mid(57)$ & $69(43)$ & \\
\hline \multicolumn{5}{|l|}{ Medical history } \\
\hline Heart Failure, n (\%) & $212(91)$ & $58(8 I)$ & $154(96)$ & $<0.001$ \\
\hline Ischemic heart disease, n (\%) & III (48) & $40(56)$ & 71 (44) & 0.1 \\
\hline Valvular disease, n (\%) & II 3 (49) & $25(35)$ & $88(55)$ & 0.004 \\
\hline Rheumatologic disease, n (\%) & $7(3)$ & I (I) & $6(4)$ & 0.5 \\
\hline Chronic AF, n (\%) & $73(31)$ & $19(26)$ & $54(34)$ & 0.2 \\
\hline Stroke/TIA, n (\%) & $10(4)$ & $4(6)$ & $6(4)$ & 0.7 \\
\hline PAD, n (\%) & $19(8)$ & $7(10)$ & $12(7)$ & 0.5 \\
\hline Anemia, n (\%) & $68(29)$ & $16(22)$ & $52(32)$ & 0.1 \\
\hline COPD, n (\%) & $42(18)$ & $8(I I)$ & $34(2 I)$ & 0.06 \\
\hline CKD, n (\%) & $58(25)$ & $18(25)$ & $40(25)$ & 0.9 \\
\hline Liver disease, n (\%) & $4(2)$ & $0(0)$ & $4(2)$ & - \\
\hline Thyroid disorders, n (\%) & $7(3)$ & $4(6)$ & $8(5)$ & 0.8 \\
\hline \multicolumn{5}{|l|}{ Risk factors for atherosclerosis } \\
\hline Smoking, n (\%) & $75(32)$ & $21(29)$ & $54(34)$ & 0.5 \\
\hline Hypertension, n (\%) & $220(94)$ & $70(97)$ & $150(93)$ & 0.3 \\
\hline Dyslipidemia, $n(\%) ; n=228$ & $152(67)$ & $54(79)$ & $98(6 I)$ & 0.007 \\
\hline Diabetes mellitus, n (\%) & $86(37)$ & $29(40)$ & $57(35)$ & 0.4 \\
\hline \multicolumn{5}{|c|}{ Clinical parameters on presentation } \\
\hline Acute de novo HF, n (\%) & $23(10)$ & $14(19)$ & $9(6)$ & \\
\hline & & & & 0.001 \\
\hline Acute on chronic HF, n (\%) & $210(90)$ & $58(8 I)$ & $152(94)$ & \\
\hline
\end{tabular}


Table Continued...

\begin{tabular}{|c|c|c|c|c|}
\hline & Overall (n: 233) & $\begin{array}{l}\text { AHF with ACS n=72 } \\
(31 \%)\end{array}$ & $\begin{array}{l}\text { AHF without ACS } n=|6| \\
(69 \%)\end{array}$ & $P$ value \\
\hline NYHA class I-II, n (\%) & $8(3)$ & $7(10)$ & I (I) & 0.001 \\
\hline NYHA class III-IV, n (\%) & $225(97)$ & $65(90)$ & $160(99)$ & 0.001 \\
\hline BMI, kg/m²; median (IQR) & $31(28-33)$ & $30.5(28-33)$ & 31 (29-33) & $0.6 * *$ \\
\hline SBP; mean \pm SD & $132 \pm 24$ & $135 \pm 22$ & $|3| \pm 24$ & $0.3^{*}$ \\
\hline $\mathrm{DBP} ;$ mean $\pm \mathrm{SD}$ & $79 \pm 14$ & $80 \pm 15$ & $79 \pm 13$ & $0.5^{*}$ \\
\hline $\mathrm{HR}$; mean $\pm \mathrm{SD}$ & $90 \pm 20$ & $88 \pm 20$ & $91 \pm 20$ & $0.2 *$ \\
\hline \multicolumn{5}{|l|}{ Electrocardiography } \\
\hline AF/Flutter, n (\%) & $77(33)$ & $20(28)$ & $57(35)$ & 0.2 \\
\hline QRS $\geq 120$ msec, n (\%) & $24(10)$ & II (I5) & $13(8)$ & 0.09 \\
\hline LBBB, n (\%) & $19(8)$ & II (I5) & $8(5)$ & 0.007 \\
\hline \multicolumn{5}{|l|}{ Biochemical parameters } \\
\hline Sodium, mEq/L; media $\pm \mathrm{DS}$ & $136 \pm 4,6$ & $136.9 \pm 4.8$ & $135.6 \pm 4.5$ & $0.05^{*}$ \\
\hline Sodium < 135 mEq/L, n (\%) & $81(35)$ & $18(25)$ & $63(39)$ & 0.03 \\
\hline Potassium; mEq/L $\pm D S$ & $4.2 \pm 0.7$ & $4.2 \pm 0.7$ & $4.3 \pm 0.6$ & $0.3^{*}$ \\
\hline Urea, mg/dl & $81.1 \pm 59.9$ & $81.1 \pm 67.1$ & $81.2 \pm 56.7$ & $0.9 *$ \\
\hline Creatinine, g/dl & $1.8 \pm 1.8$ & $2 \pm 2$ & $1.7 \pm 1.7$ & $0.3^{*}$ \\
\hline eGFR, mg/ml/l.73 m2; mean \pm SD & $62.2 \pm 36.9$ & $58.3 \pm 34.3$ & $63.9 \pm 38$ & $0.2^{*}$ \\
\hline eGFR <60 mg/ml/l.73 m2, n (\%) & $113(49)$ & $32(44)$ & $81(50)$ & 0.4 \\
\hline Hemoglobin, g/dl; mean \pm SD & $12.1 \pm 2.8$ & $12.6 \pm 2.7$ & $12 \pm 2.9$ & $0.1 *$ \\
\hline Glycemia, mg/dl; mean \pm SD & $130.2 \pm 64.9$ & $142.4 \pm 7 \mid .8$ & $|24.8 \pm 6|$ & $0.05^{*}$ \\
\hline Albumin, mg/dl; mean \pm SD. $n=I 77$ & $3 \pm 0.5$ & $3.1 \pm 0.6$ & $3 \pm 0.5$ & $0.8^{*}$ \\
\hline NT-PRO-BNP elevated, $n(\%), n=4$ & $4(2)$ & $\mathrm{I}(\mathrm{I})$ & $3(2)$ & 0,7 \\
\hline Positive troponin, $n(\%) ; n=120$ & $59(49)$ & $58(83)$ & $7(14)$ & $<0.001$ \\
\hline \multicolumn{5}{|l|}{ Echocardiography $n=228$} \\
\hline $\mathrm{EF} \%$, mean $\pm \mathrm{SD}$ & $49 \pm 14$ & $48 \pm 14$ & $50 \pm 15$ & $0.1 *$ \\
\hline$E F \geq 50 \%, n(\%)$ & $116(51)$ & $32(46)$ & $84(53)$ & 0.2 \\
\hline$E F<50 \%, n(\%)$ & II 2 (49) & $38(54)$ & $74(47)$ & \\
\hline
\end{tabular}

* T-test

** Kruskal Wallis

Abbreviations: ACS, acute coronary syndrome; AF, atrial fibrillation; AHF, acute heart failure; BMI, body mass index; COPD, chronic obstructive pulmonary disease; CKD, chronic kidney disease; DBP diastolic blood pressure; EF, ejection fraction; eGFR, estimated glomerular filtration rate; HR, hear rate; LBBB, left bundle branch block; NYHA, New York Heart Association functional class; PAD peripheral artery disease; SBP systolic blood pressure; TIA, transient ischemic accident Ischemic heart disease was more common in the acute HF with ACS cohort $(p=0.1)$, as well as risk factors for atherosclerotic disease such as Hypertension $(p=0.3)$, dyslipidemia $(p=0.007)$ and diabetes mellitus $(p=0.4)$. Smoking or smoking history $(p=0.5)$ was more frequent in the acute HF without ACS cohort, as well as the history of cerebrovascular disease, peripheral arterial disease and thyroid disease were more frequent in this cohort. 
Table 3 Treatments received and procedures performed during hospitalization in patients with AHF with and without ACS

\begin{tabular}{|c|c|c|c|c|}
\hline & Overall $n=233$ & AHF with ACS $n=72$ (3I\%) & $\begin{array}{l}\text { AHF without ACS } n=161 \\
(69 \%)\end{array}$ & $P$ value \\
\hline \multicolumn{5}{|l|}{ Treatments } \\
\hline ACEI, n (\%) & $100(43)$ & $30(42)$ & $70(43)$ & 0.7 \\
\hline ARB, n (\%) & $40(17)$ & $10(14)$ & $30(19)$ & 0.3 \\
\hline Aldosterone antagonist, n (\%) & $88(38)$ & $12(17)$ & $76(47)$ & $<0.00$ I \\
\hline Beta-blockers, n (\%) & $154(66)$ & $53(74)$ & $10 \mid(63)$ & 0.1 \\
\hline Loop diuretics, n (\%) & $226(97)$ & $66(92)$ & $160(99)$ & 0.005 \\
\hline Inotropic, n (\%) & $28(12)$ & $9(12)$ & $19(12)$ & 0.8 \\
\hline Vasopressors, n (\%) & $26(11)$ & $10(14)$ & $16(10)$ & 0.3 \\
\hline \multicolumn{5}{|l|}{ Procedures } \\
\hline Coronary angiography, n (\%) & $35(15)$ & $26(36)$ & $9(6)$ & $<0.001$ \\
\hline Non-significant CAD, n (\%); n=35 & $12(34)$ & $8(3 I)$ & $4(44)$ & 0.7 \\
\hline Single-vessel CAD, $n(\%) ; n=35$ & $4(I I)$ & $4(15)$ & 0 & 0.5 \\
\hline Double-vessel CAD, n (\%); $\mathrm{n}=35$ & $6(17)$ & $5(19)$ & $\mathrm{I}(\mathrm{II})$ & 0.9 \\
\hline Three-vessel CAD, n (\%); n=35 & $13(37)$ & $9(35)$ & $4(44)$ & 0.8 \\
\hline $\mathrm{PCl}, \mathrm{n}(\%) ; \mathrm{n}=23$ & $2(1)$ & $2(I I)$ & 0 & 0.8 \\
\hline
\end{tabular}

Table 4 Clinical outcomes during hospitalization in acute HF

\begin{tabular}{|c|c|c|c|c|c|}
\hline & $\begin{array}{l}\text { Overall } \\
n=233\end{array}$ & $\begin{array}{l}\text { AHF with ACS } \\
n=72(31 \%)\end{array}$ & $\begin{array}{l}\text { AHF without ACS } \\
n=161(69 \%)\end{array}$ & RR (Cl 95\%) & $P$ value \\
\hline Overall shock, n (\%) & $42(18)$ & $15(21)$ & $27(17)$ & I.2 (0.7-2.I) & 0.4 \\
\hline Cardiogenic shock, n (\%) & $21(9)$ & $7(10)$ & $14(9)$ & I.I (0.4-2.6) & 0.8 \\
\hline Non-cardiogenic shock, n (\%) & $5(2)$ & $2(3)$ & $3(2)$ & I.4 (0.2-8.7) & 0.9 \\
\hline Mixed shock, n (\%) & $17(7)$ & $7(10)$ & $10(6)$ & $1.5(0.6-3.94)$ & 0.3 \\
\hline VT/VF, n (\%) & $6(3)$ & $2(3)$ & $4(2)$ & I.I (0.2-5.9) & 0.7 \\
\hline Stroke, n (\%) & $3(1)$ & $2(3)$ & I (I) & $4.4(0.4-48.5)$ & 0.4 \\
\hline Major bleeding, n (\%) & $2(1)$ & $I(I)$ & I (I) & $2.2(0.1-35.2)$ & 0.8 \\
\hline Cardiorenal syndrome, n (\%) & $15(6)$ & $5(7)$ & $10(6)$ & I.I $(0.3-3.1)$ & 0.8 \\
\hline Hemodialysis requirement, $\mathrm{n}(\%)$ & $14(6)$ & $4(6)$ & $10(6)$ & $0.8(0.2-2.7)$ & 0.9 \\
\hline Acute Pulmonary Edema, n (\%) & $24(10)$ & $8(I I)$ & $16(10)$ & I.I (0.5-2.4) & 0.7 \\
\hline Sepsis, n (\%) & $16(7)$ & $2(3)$ & $14(9)$ & $0.3(0.07-I .3)$ & 0.1 \\
\hline ICU requirement, n (\%) & $7(3)$ & $2(3)$ & $5(3)$ & $0.8(0.1-4.5)$ & 0.7 \\
\hline Days of hospitalization, mean \pm SD & $12 \pm 8$ & $12 \pm 9$ & $12 \pm 8$ & & $0.9^{*}$ \\
\hline MI, n (\%) & $3(1)$ & 0 & $3(2)$ & NC & \\
\hline Emergencycardiac surgery, n (\%) & $3(1)$ & 0 & $3(2)$ & NC & \\
\hline Complete heart block, n (\%) & $2(I)$ & I (I) & I (I) & $2.2(0.1-35.2)$ & 0.8 \\
\hline Global death, n (\%) & $30(13)$ & II (I5) & $19(12)$ & I.2 (0.6-2.5) & 0.4 \\
\hline Cardiovascular death, $n(\%) ; n=30$ & $15(50)$ & $6(55)$ & $9(47)$ & I.I (0.5-2.3) & 0.7 \\
\hline Sudden death, $n(\%), n=30$ & $5(17)$ & $3(27)$ & $2(I I)$ & $2.5(0.5-13.1)$ & 0.4 \\
\hline $\begin{array}{l}\text { Death of multifactorial cause, } n \\
(\%) ; n=30\end{array}$ & $13(43)$ & $5(45)$ & $8(42)$ & I $(0.4-2.4)$ & 0.8 \\
\hline Death by sepsis, $n$ (\%); $n=30$ & $2(7)$ & 0 & $2(I I)$ & NC & \\
\hline
\end{tabular}

*T-test

Abbreviations: ACS, acute coronary syndrome; AHF, acute heart failure; ICU, intensive care unit; MI, myocardial infarction; NC, not calculable; VF, ventricular fibrillation; TV, ventricular tachycardia 
However, patients with ACS were more susceptible to develop shock during hospitalization (cardiogenic, non-cardiogenic and mixed), with a RR of $1.2(0.7-2.1)$ for the overall shock $(\mathrm{p}=0.4)$. Complications such as acute pulmonary edema, malignant ventricular arrhythmias, stroke, and cardiorrenal syndrome were more frequent in patients with acute HF with ACS. Other complications such as: major bleeding, hemodialysis requirement, complete heart block, mechanical ventilation requirement and admission to intensive care unit were similar in both groups. Hospital-acquired infection, myocardial infarction, emergency cardiac surgery were more frequent in acute HF without ACS patients. Days of hospitalization were similar in both groups, mean $12 \pm 8(\mathrm{p}=0.9)$.

We did not find significant differences in terms of overall mortality, RR of $1.2(0.6-2.5)(\mathrm{p}=0.4)$. However, cardiovascular death, multifactorial death, and sudden death were more frequent in patients in the acute HF with ACS group. Septic deaths were more frequent in patients without ACS.

\section{Discussion}

In this study we compared the results of patients admitted to the hospital with acute heart failure triggered by acute coronary syndrome opposed to cases of acute heart failure due to a different trigger. Approximately $30 \%$ of the total enrolled patients belonged to the acute HF with ACS cohort, which agrees with the findings of previous studies. ${ }^{21-28}$ The patients belonging to this cohort were on average older, had more associated cardiovascular risk factors, which was consistent with the greater history of ischemic heart disease. ${ }^{29-33}$ In addition, they had fewer associated comorbidities, and at the time of hospital admission they were more likely to have de novo acute HF compared with patients without ACS.

In contrast, patients without ACS had a history of chronic heart failure, and therefore presented in almost all cases as an exacerbation of heart failure. Among the biochemical parameters of both groups, significant differences were not found, therefore, comparable for the purpose of the study. Regarding the treatments received, no significant differences were found for most of them, which would be explained by the similar management of coronary syndrome and heart failure. ${ }^{1,2,20-23}$ On the other hand, there were differences regarding the use of loop diuretics and antialdosterone diuretics, which predominated in patients without ACS, this could be explained by the higher proportion of patients with chronic heart failure in this group, because the congestive symptoms are more frequent in this entity.

There were no differences regarding the days of hospitalization. It is expected that the group with ACS have a longer hospital stay according to previous studies. ${ }^{34}$ The reason why patients without ACS presented similar days of hospitalization could be explained by the high proportion of the infectious cause as precipitants of acute HF in this group, in addition they presented more frequently hospitalacquired infection, which supposes the requirement of several days of hospitalized antibiotic treatment. We did not find significant differences in hospital adverse cardiovascular outcomes comparing both groups, however, patients with ACS required more vasopressors, so we can assume a more aggressive course of this entity ${ }^{35}$ which relates with an increased frequency of overall shock, excepting septic shock, for reasons previously discussed. Other complications were also recorded more frequently in these patients, such as the appearance of malignant arrhythmias, stroke, renal failure, although the requirement for rescue hemodialysis was similar in both groups, possibly due to the greater history of chronic renal failure in the group without ACS.

The requirement for mechanical ventilation and admission to the ICU was similar in both cohorts. Three events of myocardial infarction were recorded in the in-hospital setting in 3 patients belonging to the group without ACS. This was associated with worse evolution during hospitalization, all of them were complicated by cardiogenic shock, 2 died during hospitalization, and the other patient required mechanical ventilation and admission to the ICU, leading us to suppose that infarction represented a triggering event for the appearance of complications in this group of patients.

Emergency cardiac surgery was only performed in 3 patients without ACS, due to the etiology of heart failure, 2 of them of valvular cause secondary to endocarditis requiring valve replacement intervention, and another patient due to cardiac tamponade requiring surgical pericardiectomy. There were no significant differences when comparing the mortality between both groups; however, greater tendency was found in patients with ACS. Overall in-hospital mortality was $13 \%$, comparable with other reports. ${ }^{31,32}$ The acute HF cohort with ACS presented a greater proportion of cardiovascular death, death of multifactorial cause and sudden death, which is related to the worse prognosis in this entity.

With these findings we could assume that an acute coronary event represents a strong risk factor for the appearance of major adverse cardiovascular events in patients with acute HF during the course of the disease ${ }^{(36)}$. Therefore, a strategy for early diagnosis, risk stratification, and early initiation of aggressive therapy could improve the prognosis of this group of patients.

The limitations of this study are that they represent only the tendency of a single hospital center, while the reports referring to this topic were carried out in a multicentric and multinational manner with the recruitment of a much higher sample. However, the proportion of patients with acutr HF with and without ACS in this study, as well as the results found are to a large extent comparable with previous studies. ${ }^{13,14,30-33} \mathrm{We}$ did not find a national or a regional record related to the subject of this study, so this report would be useful as an initiative for future research, in order to have a registration system on a very prevalent disease with high morbidity and mortality.

\section{Conclusion}

Adverse cardiovascular outcomes were more frequent in patients with ACS. These patients were more likely to suffer shock, especially cardiogenic and mixed shock type. In addition, these patients developed more frequently acute pulmonary edema, cardiorenal syndrome, stroke and malignant arrhythmias. All causes of death were more prevalent in patients with ACS, especially cardiovascular death. The most frequent precipitating causes of acute HF were nonadherence to medication, infection, ACS, arrhythmias, especially tachyarrhythmias, and valvular etiology, among others.

We can conclude that ACS as a precipitating factor of HF is a distinct clinical entity, with a particular Pathophysiology and a different clinical outcome compared with other causes of heart failure. In addition, it is associated with more adverse cardiovascular events in the evolution, therefore, it should be considered for the early initiation of therapeutic strategies in order to improve the prognosis of this group of patients. 


\section{Acknowledgements}

None.

\section{Conflict of interest}

The author declares that there is no conflict of interest.

\section{References}

1. Ponikowski P, Voors AA, Anker SD, et al. 2016 ESC Guidelines for the Diagnosis and Treatment of Acute and Chronic Heart Failure. Rev Esp Cardiol (Engl Ed). 2016;69(12):1167.

2. Yancy CW, Jessup M, Bozkurt B, 2013 ACCF/AHA guideline for the management of heart failure: executive summary: a report of the American College of Cardiology Foundation/American Heart Association Task Force on practice guidelines. Circulation. 2013;128(16):1810-1852.

3. Martindale, Jennifer L.Wakai, et al. Diagnosing Acute Heart Failure in the Emergency Department: A Systematic Review and Meta- analysis. Academic Emergency Medicine. 2016;23(2):223-242.

4. Ponikowski P, Jankowska E. Patogenia y presentación clínica de la insuficiencia cardiaca aguda. Rev Esp Cardiol. 2015; 68(4):331-337.

5. AlHabib KF, Elasfar AA, Alfaleh H, et al. Clinical features, management, and short- and long-term outcomes of patients with acute decompensated heart failure: phase I results of the HEARTS database. Eur J Heart Fail. 2014;16(4):461-469.

6. Panduranga P, Sulaiman K, Al-Zakwani I, et al. Demographics, Clinical Characteristics, Management, and Outcomes of Acute Heart Failure Patients: Observations from the Oman Acute Heart Failure Registry. Oman Med J. 2016;31(3):188-195.

7. Gysele S. Bleuminka, Anneke M. et al. Strickera. Quantifying the heart failure epidemic: prevalence, incidence rate, lifetime risk and prognosis of heart failure The Rotterdam Study. European Heart Journal. 2004; 25(18):1614-1619.

8. Fonarow GC, Abraham WT, Albert NM, et al. Influence of a PerformanceImprovement Initiative on Quality of Care for Patients Hospitalized With Heart FailureResults of the Organized Program to Initiate Lifesaving Treatment in Hospitalized Patients With Heart Failure (OPTIMIZE-HF). Arch Intern Med. 2007;167(14):1493-502.

9. Parenica J, Spinar J, Vitovec J, et al. Long-term survival following acute heart failure: The Acute Heart Failure Database Main registry (AHEAD Main). European Journal of Internal Medicine. 2013;24(2):151-160.

10. Purek L, Laule-Kilian K, Christ A, et al. Coronary artery disease and outcome in acute congestive heart failure. Heart. 2006;92(5):598-602.

11. Nieminen MS, Brutsaert D, Dickstein K, et al. EuroHeart Failure Survey II (EHFS II): a survey on hospitalized acute heart failure patients: description of population. Eur Heart J. 2006;27(22):2725-2736.

12. Steg PG, Dabbous OH, Feldman LJ, et al. Determinants and prognostic impact of heart failure complicating acute coronary syndromes: observations from the Global Registry of Acute Coronary Events (GRACE). Circulation. 2004;109(4):494- 499.

13. AlFaleh $\mathrm{H}$, Elasfar AA, Ullah A, et al. Acute heart failure with and without acute coronary syndrome: clinical correlates and prognostic impact (From the HEARTS registry). BMC Cardiovasc Disord. 2016;16:98.

14. Tarvasmäki T, Harjola VP, Nieminen MS, et al. Acute heart failure with and without concomitant acute coronary syndromes: patient characteristics, management, and survival. J Card Fail. 2014;20(10):723-730.

15. Djousse L, Driver JA, Gaziano JM. Relation between modifiable lifestyle factors and lifetime risk of heart failure. JAMA. 2009;302:394-400.
16. Maggioni AP, Dahlström U, Filippatos G, et al. EURObservational Research Programme: regional differences and 1-year follow-up results of the Heart Failure Pilot Survey (ESC-HF Pilot). Eur J Heart Fail. 2013;15:808-817.

17. Crespo-Leiro MG, Anker SD, Maggioni AP, et al. Heart Failure Association (HFA) of the European Society of Cardiology (ESC). European Society of Cardiology Heart Failure Long-Term Registry (ESC-HF-LT): 1-year follow-up outcomes and differences across regions. Eur J Heart Fail. 2016;18(6):613-625.

18. Ammar KA, Jacobsen SJ, Mahoney DW, et al. Prevalence and prognostic significance of heart failure stages: application of the American College of Cardiology/American Heart Association heart failure staging criteria in the community. Circulation. 2007;115(12):1563-1570.

19. Felker GM, Mentz RJ, Teerlink JR, et al. Serial high sensitivity cardiac troponin $\mathrm{T}$ measurement in acute heart failure: insights from the RELAXAHF study. Eur J Heart Fail. 2015;17(12):1262-1270.

20. O'Gara PT, Kushner FG, Ascheim DD, et al. 2013 ACCF/AHA guideline for the management of ST-elevation myocardial infarction: executive summary: a report of the American College of Cardiology Foundation/ American Heart Association Task Force on Practice Guidelines. J Am Coll Cardiol. 2013;61(4):485-510.

21. Amsterdam EA, Wenger NK, Brindis RG, et al. 2014 AHA/ACC Guideline for the Management of Patients with Non-ST-Elevation Acute Coronary Syndromes: a report of the American College of Cardiology/ American Heart Association Task Force on Practice Guidelines. J Am Coll Cardiol. 2014;64(24):e139-228.

22. Ibanez B, James S, Agewall S, et al. 2017 ESC Guidelines for the management of acute myocardial infarction in patients presenting with ST-segment elevation: The Task Force for the management of acute myocardial infarction in patients presenting with ST-segment elevation of the European Society of Cardiology (ESC). Eur Heart J. 2017; 39(2):119-177.

23. Roffi M, Patrono C, Collet JP, et al. 2015 ESC Guidelines for the Management of Acute Coronary Syndromes in Patients Presenting Without Persistent ST-segment Elevation. Rev Esp Cardiol (Engl Ed). 2015;68(12):1125.

24. Konstantinides SV, Torbicki A, Agnelli G, et al. 2014 ESC guidelines on the diagnosis and management of acute pulmonary embolism. Eur Heart J. 2014;35(43):3033-3069, 3069a-3069k.

25. Mebazaa A, Yilmaz MB, Levy P, et al. Recommendations on pre-hospital \& early hospital management of acute heart failure: a consensus paper from the Heart Failure Association of the European Society of Cardiology, the European Society of Emergency Medicine and the Society of Academic Emergency Medicine. Eur J Heart Fail. 2015;17(6):544-558.

26. Prins KW, Neill JM, Tyler JO, et al. Effects of Beta-Blocker Withdrawal in Acute Decompensated Heart Failure: A Systematic Review and MetaAnalysis. JACC Heart Fail. 2015;3(8):647-653.

27. Faris RF, Flather M, Purcell H, et al. Diuretics for heart failure. Cochrane Database Syst Rev. 2012;1:CD003838.

28. King JB, Bress AP, Reese AD, et al. Neprilysin inhibition in heart failure with reduced ejection fraction: a clinical review. Pharmacother J Hum Pharmacol Drug Ther. 2015;35(9):823-837.

29. McMurray JJ, Packer M, Desai AS, et al. Dual angiotensin receptor and neprilysin inhibition as an alternative to angiotensin-converting enzyme inhibition in patients with chronic systolic heart failure: rationale for and design of the Prospective comparison of ARNI with ACEI to Determine Impact on Global Mortality and morbidity in Heart Failure trial (PARADIGM-HF). Eur J Heart Fail. 2013;15(9):1062-1073. 
30. Sulaiman K, Panduranga P, Al-Zakwani I, et al. Rationale, Design, Methodology and Hospital Characteristics of the First Gulf Acute Heart Failure Registry (Gulf CARE). Heart Views. 2014 Jan;15(1):6-12.

31. Spinar J, Parenica J, Vitovec J, et al. Baseline characteristics and hospital mortality in the Acute Heart Failure Database (AHEAD) Main registry. Crit Care. 2011;15(6):R291.

32. Follath F, Yilmaz MB, Delgado JF, et al. Clinical presentation, management and outcomes in the Acute Heart Failure Global Survey of Standard Treatment (ALARM-HF). Intensive Care Med. 2011;37(4):619626.

33. Greenberg G, Cohen E, Garty M, et al. Outcomes of acute heart failure associated with acute coronary syndrome versus other causes. Acute Card Care. 2011;13(2):87-92.
34. Shah RV, Holmes D, Anderson M, et al. Risk of heart failure complication during hospitalization for acute myocardial infarction in a contemporary population: insights from the National Cardiovascular Data ACTION Registry. Circ Heart Fail. 2012;5(6):693-702.

35. Flaherty JD, Bax JJ, De Luca L, et al. Acute Heart Failure Syndromes International Working Group. Acute heart failure syndromes in patients with coronary artery disease early assessment and treatment. J Am Coll Cardiol. 2009;53(3):254-263.

36. Sulo G, Igland J, Nygard O, et al. Prognostic Impact of In-Hospital and Postdischarge Heart Failure in Patients With Acute Myocardial Infarction: A Nationwide Analysis Using Data From the Cardiovascular Disease in Norway (CVDNOR) Project. J Am Heart Assoc. 2017;15;6(3):e005277. 